\title{
Veterinary Considerations for the Theoretical Resurrection of Extinct Species
}

Feye $\mathrm{KM}^{\# 1}$, Smith $\mathrm{JS}^{\# 2}$, Sebbag L ${ }^{\# 1}$, Hohman $\mathrm{AE}^{\# 1}$, Acharya ${ }^{\# 1}$, Schneider BK ${ }^{\# 1}$, Tucker JT ${ }^{\# 3}$, Cherep LA ${ }^{\# 3,4}$, Nordeng $\mathrm{BR}^{\# 1}$, Richardson $\mathrm{AL}^{\# 1}$, Gage $\mathrm{MC}^{\# 3}$, Luo $\mathrm{D}^{1}$, Shrestha $\mathrm{D}^{1}$, Izbicki $\mathrm{P}^{3,5}$, Malovic $\mathrm{E}^{1,3}$, Jefferson $\mathrm{MA}^{3,5}$, Manne $\mathrm{S}^{1}$, Jaisil $\mathrm{P}^{3,6}$, Kondru $\mathrm{NC}^{1}$, Massey $\mathrm{N}^{1}$, Klinedinst $\mathrm{BS}^{3,5}$ and Carlson $\mathrm{SA}^{{ }^{* 1}}$

*These authors had equal contributions

${ }^{1}$ Department of Biomedical Sciences, Iowa State University College of Veterinary Medicine, Ames, Iowa, USA

${ }^{2}$ Department of Veterinary Diagnostic and Production Animal Medicine, Iowa State University College of Veterinary

Medicine, Ames, Iowa, USA

${ }^{3}$ Neuroscience Interdepartmental Program, Iowa State University, Ames, Iowa, USA

${ }^{4}$ Department of Psychology, Iowa State University College of Liberal Arts and Sciences, Ames, Iowa, USA

${ }^{5}$ Department of Kinesiology, Iowa State University College of Liberal Arts and Sciences, Ames, Iowa, USA

${ }^{6}$ Department of Biochemistry, Biophysics and Molecular Biology, Iowa State University College of Liberal Arts and Sciences, Ames, Iowa, USA

*Corresponding author: Carlson SA, Department of Biomedical Sciences, Iowa State University College of Veterinary Medicine, Ames, IA 50011, Iowa, USA, Fax: 515-294-2315, Tel: 515-294-0912, E-mail: stevec@ iastate.edu

Citation: Feye KM, Smith JS, Sebbag L, Hohman AE, Acharya S, et al. (2018) Veterinary Considerations for the Theoretical Resurrection of Extinct Species. J Vet Sci Ani Husb 6(3): 306. doi: 10.15744/2348-9790.6.306

Received Date: August 04, 2018 Accepted Date: August 22, 2018 Published Date: August 24, 2018

\begin{abstract}
The de-extinction of the dinosaur is a dubious possibility but its consideration brings forth some issues that are at least worthy of scientific discussion. In this review, we discuss two distinct issues that have implications for a de-extinct species such as a dinosaur: the ability, or lack thereof, to safely sedate a rare and potentially fractious animal capable of harming the veterinary staff tasked with its care; and, disease risks associated with a species that has been extinct for millions of years. To identify potential sedatives, comparative pharmacology will be needed to uncover the links between receptor pharmacology and the desired clinical outcomes of activating established alpha-2 adrenergic, opioid, and benzodiazepine receptors. Specific to disease control, it will be necessary to understand the unique susceptibility of the new species to current diseases as well as predicting their reservoir capacity for potential human and veterinary pandemic diseases. While the topics presented herein are not exhaustive, this review highlights some of the foremost research that should be conducted in order to serve the unique veterinary needs of a de-extinct species using the dinosaur as a paradigm. Addressing these issues should be considered if an intact dinosaur genome becomes available, regardless of the feasibility of dinosaur resurrection.
\end{abstract}

Keywords: De-Extinction; Receptor; Comparative Pharmacology; Genetic Divergence; Infection Control

\section{Introduction}

Specimens from the fossil record have captivated generations of mankind. Advances in molecular technologies have enabled the recent cloning-based resurrection of an extinct species (the Pyrenean ibex) as well as providing the theoretical framework for re-creating the woolly mammoth [1]. While the return of dinosaurs is highly debatable, attempts to do so come with great responsibility [2]. A plethora of issues should be considered if an intact genome becomes available, even if it is just an academic exercise. Beyond the bioethics of the de-extinction of any species, there are significant concerns regarding dinosaur veterinary needs that range from analgesia, anesthesia, and euthanasia through the mollification of zoonotic and dinosaur-specific diseases.

It is prudent to perform explicit investigations aimed to interrogate potential pharmacologic agents used to control fractious or intractable dinosaurs. A comparative pharmacologic approach will need to be employed, using the current understanding of tranquilizers, sedatives, and narcotics across extant species in order to understand the potential applications to extinct species [3]. Specifically, a comparative approach should be used to identify evolutionarily conserved motifs in the cognate receptors for drugs such as alpha-2-adrenergic agonists, benzodiazepine receptor agonists, and opioid receptor agonists.

The conceivable threat of zoonosis and endemic diseases should also be carefully considered, as the epidemiological impact of 
de-extinction of dinosaurs could generate globally catastrophic consequences. For example, the American alligator, which has remained relatively unchanged since prehistoric times, serves as a potent amplifier of the West Nile virus that causes a zoonotic encephalopathy of humans [4]. In the same manner, dinosaurs could serve as vectors of both known, as in the case of the American alligator, and unknown infectious diseases [5]. A stringent comparative approach should be considered for screening potential global health issues that could ensue upon the return of the dinosaurs.

Furthermore, certain modern-day diseases could present severe health threats to species reversed from extinction. This issue is all the more concerning given the lack of genetic diversity in clonally de-extinct dinosaurs which may result in greater susceptibility to infectious diseases [6]. Heightened risks of disease faced by dinosaurs could be both pre-historic diseases that have analogs in the modern era and modern diseases that are not part of the fossil record [7-9]. Due diligence would dictate that modern-day diseases must be rigorously vetted before attempting to bring back the dinosaur.

The purpose of this review is to outline some lines of research to be investigated in consideration of the de-extinction process using the dinosaur as the paradigm. That is, we are not advocating such an endeavor but we recognize the possibility and propose new fields of study that could be dubbed as "paleopharmacology" and "paleoepidemiology". The goal of this review is to merely elucidate some of the crucial information to be acquired in the advent of the discovery or artificial creation of an intact dinosaur genome.

\section{Alpha-2 Adrenergic Receptors in the De-extinct Species}

Alpha-2 adrenoreceptor agonists (or a2-agonists), including xylazine, romifidine, (dex) medetomidine, and detomidine, are widely used sedatives in veterinary species [10]. A significant advantage of this drug group is the reversibility of sedation by specific a2-antagonists (e.g., yohimbine and atipamezole), allowing for a more rapid recovery and prevention of the potentially fatal cardiovascular side effects of a2-agonists [3,10]. However, the depth of sedation and side effects varies across species and members of the drug class. This variability is especially relevant to dinosaurs given the inconsistent sedative effects across birds and reptiles [11]. The rapid onset and reversibility of these drugs underscore the relevance of investigating their properties in a new species.

Molecular studies indicate that $\alpha 2$ receptors primarily consist of three homologous subtypes: $a 2 \mathrm{~A}, \alpha 2 \mathrm{~B}$, and $\alpha 2 \mathrm{C}$ [10]. Speciesspecific variations in subtypes of receptors and anatomical loci could explain varying degrees of sedation and adverse effects across veterinary species [3,11-14]. For instance, intramuscular medetomidine does not fully immobilize pigeons and Amazon parrots but can induce surgical anesthesia in some reptiles whereas xylazine appears to be efficacious across birds and reptiles [15-17]. Likely these diverging responses are based on 22 receptor amino acid sequence heterogeneity that dictate agonist/antagonist affinities for the receptor and the resulting signal transduction events that mediate the clinical effects of the drugs [18]. Therefore, it will be imperative to interrogate these molecular parameters for the dinosaur $a 2$ adrenergic receptor. Addressing this issue may involve comparative pharmacologic studies involving heterologous expression systems in which all of the known $\alpha 2$ adrenergic receptors are examined for agonist and antagonist activities, i.e., binding affinities and signal-transducing capabilities. These data will need to be concatenated and compared to data obtained from similar assays with the predicted dinosaur $a 2$ adrenergic receptor [3,12]. These molecular findings will need to be compared to established clinical outcomes in mammalian, avian, and reptilian species.

Given the species-specific heterogeneity of $\alpha 2$ adrenergic receptors and possible fatal adverse effects of $\alpha 2$-agonists, their use in dinosaurs should be preceded by a comprehensive and comparative assessment of receptor-specific responses to various drugs. The heterologous expression studies will allow for the correlation of clinical outcomes with molecular pharmacologic responses, and similarities therein will provide the basis for selecting the optimal pairing of an agonist and antagonist.

\section{Opioid Receptors in the De-extinct Species}

Opioids such as morphine, methadone, fentanyl, and carfentanil are primarily used for their analgesic and sedative properties, with established efficacies for tranquilizing large fractious animals such as bison, lions, and ostriches [10,19-21]. For these reasons, opioids would be candidate drugs for use in a large de-extinction species revived in an unfamiliar environment; however, the effects of opioids in non-mammalian species are not well understood. A specific clinical example is the finding that opioids can cause hyperalgesia rather than hypoalgesia, as exemplified by the use of morphine and codeine in chicks [22]. This discrepant effect underscores the unpredictability of opioids in non-mammalian species and thus the need to delineate their effects outside of mammals.

In vertebrate species, opioids bind $m u$, kappa, and delta opioid receptors whereby mu receptors are most commonly implicated in analgesia and sedation [23]. Although non-mammalian species possess the same three types of opioid receptors as mammals, large differences exist between these two groups in the binding affinities of selective opioid receptor agonists [24]. The amino-acid sequence of opioid receptors is key information that must be acquired from the new species and compared to opioid receptors in contemporary species with known binding affinities to useful agonists. It should be noted, however, that the complete genomic and proteomic sequences of the main three opioid receptor types are not currently available for reptiles and avian species which is necessary for a comparative pharmacology approach [24]. Bioinformatic approaches, like that used for occult G protein-coupled receptors in invertebrates, could help to uncover these receptor sequences [25].

Interrogating the drug-receptor interactions is especially relevant given the new information about opioid receptor agonists whose 
effects are not consistently reversed by the traditional opioid receptor antagonist naloxone [24]. Acrylfentanyl and oxymorphazone are synthetic opioid receptor agonists displaying such characteristics, underscoring the importance of fully understanding the reversibility of these sedatives in order to insure the safety of the animals and handlers $[26,27]$.

\section{Benzodiazepine Receptors in the De-extinct Species}

Benzodiazepines are a class of sedatives that act as allosteric modulators of $\mathrm{GABA}_{\mathrm{A}}$ receptors; these receptors are highly expressed in the cortex, thalamus and cerebellum which make them an ideal target for tranquilization [28]. Drugs such as alprazolam, lorazepam, midazolam, and diazepam could be investigated with similar comparative pharmacology methodologies as with those suggested for drugs targeting alpha-2 adrenergic receptors and opioid receptors. Midazolam is the only benzodiazepine in which comparative pharmacologic data is available- this drug yields appropriate sedation when used intranasally in parrots and intramuscularly in crocodiles, suggesting that this drug might be of consideration for a de-extinct species with avian and/or reptilian characteristics $[29,30]$. Similar to previous sections herein, identification of the amino acid sequence of GABAA receptors, specifically the motifs determining benzodiazepine binding, is critical for our understanding of how these drugs will work in a new species [3,12,31]. Binding affinities, concentration analyses, as well as the effect on GABAA receptors should be studied to be adequately prepared for use of these agents.

In conclusion, it is crucial that we find safe and effective drugs for sedation and reversal in a de-extinct species that is large and has great potential to be fractious. The classes of drugs listed in this review were deemed the most appropriate for this purpose, but we acknowledge that other receptor types could be explored.

\section{Pandemic Diseases that could be instigated by a New Species}

A topic that should be addressed when discussing the resurrection of a long-extinct species is the disease risks to other animals, including humans. Dinosaurs are likely to exhibit attributes of both avian and reptilian physiology, and as such, they may be reservoirs and/or amplifiers of several diseases with pandemic potential [4]. For example, birds have been established as hosts for West Nile virus and both alligators and crocodiles have been shown to maintain and amplify this virus [4]. Another zoonotic virus with potential pandemic considerations is the influenza virus, as numerous avian species have been implicated in the transmission of H5N1 [32]. Both of these viruses have the potential to cause widespread diseases with high morbidities and mortalities if the resurrected species were to be effective hosts.

In addition to viral diseases, several pervasive zoonotic bacterial agents could be propagated through the new species. Salmonella spp., a commensal organism in poultry and reptiles, is a common pathogen that represents a significant biohazard to humans $[33,34]$. A recent outbreak of human salmonellosis originating from a "no-contact" Komodo dragon exhibit at a Colorado zoo serves as a theoretical basis of the risk for individuals interacting with new species in the absence of direct contact with the animal [35]. Additionally, zoonotic transmission of pathogens such as Aeromonas spp., Campylobacter spp., and Mycobacterium spp. has all been linked to reptiles [5]. Pathogenesis and host response pathways, especially the host proteins targeted and/or exploited by pathogens, are not fully known for all of the aforementioned pathogens. Uncovering these host-pathogen interactions will provide a better understanding of common pathogens in avian and reptilian species, which will be of great importance in order to predict the results of such infections in a new species such as a resurrected dinosaur that has both avian an reptilian characteristics.

The process of removing nuclear DNA from a preserved dinosaur cell for replication and cloning presents the risk of replicating endogenous retroviral DNA that may be embedded within the utilized genome. The result of this retroviral integration is known to cause a myriad of clinical diseases, including immunosuppression and neoplasia, in current mammalian, avian, and reptilian species [36]. A mammalian example is Dolly the cloned sheep who died from retroviral-associated pulmonary adenocarcinoma [37]. As we cannot fully predict the impact of replicating non-dinosaur DNA in the cloning process, strict biosecurity must be practiced in facilities undertaking these cloning projects to mitigate potential disasters.

Potential infectious and zoonotic diseases from modern-day species must be vetted for the theoretical role that a new species may have as an index patient for a pandemic. Understanding which pathogens could utilize the new species as hosts will dictate research into vaccines and prophylactic measures for preventing endemic diseases before any outbreaks occur.

\section{Diseases that the New Species could be Susceptible to}

In theory, there are multiple pathogens that could present risks to a de-extinct species. These concerns are supported by evidence in the fossil record, along with established susceptibilities in related modern-day species, indicating that dinosaurs were susceptible to an array of pathogens. Agents of concern will be protozoa, nematodes, fungi, bacteria, and viruses. Further complicating this issue will be the lack of genetic diversity in the resurrected population.

Parasitic organisms are among the multiple disease-causing agents that could pose challenges to a resurrected dinosaur. The Tuatara (Sphenodon punctatus), a protected reptile in New Zealand unchanged since the time of the dinosaurs, is susceptible to potentially life-threatening anemia from the tick-vectored apicomplexan blood parasite Hepatozoon tuatarae [38]. There are species of ticks 
that have fed on reptiles for over 250 million years, but the relationship with dinosaurs is not established [39]. Nonetheless, the distinct possibility of this relationship is of concern for the health of dinosaurs.

Ascarids have been found in 240 million-year-old fossilized feces and nematode signatures have been identified in fossilized intestinal contents obtained from a dinosaur [40,41]. Additionally, trematodes and cestodes have been identified in fossilized dinosaur feces [41,42]. Modern-day birds and reptiles are frequently parasitized by the whole cadre of gastrointestinal parasites and thus it is very likely that dinosaurs would be susceptible [43]. Further complicating this problem is anthelmintic resistance and the finding that ivermectin, the single most important veterinary anthelmintic, is toxic to some reptiles [44].

Several current-day fungal pathogens may also present a significant disease risk to dinosaurs. Cold-blooded species are often at a greater risk for mycoses as lower body temperatures can facilitate mycotic replication and several modern fungal pathogens will likely present a serious risk to resurrected dinosaurs [45]. One theory contributing to the mass extinction of dinosaurs is that a widespread fungal agent disseminated after massive sporulation following a deforestation event, leading to a significant selection pressure favoring endothermic species such as birds and mammals whose basal body temperatures often prevent the replication of certain fungal agents [45]. Cryptococcus neoformans, in particular, has been implicated in the death of the dinosaur and is still a pathogen of concern today [45].

The lack of genetic diversity within the resurrected dinosaur population will likely increase their susceptibility to contemporary diseases, thus hampering their chances of long-term survival [6]. Examples of this issue are the Tasmanian tiger and Tasmanian devil, both of which have been isolated on an island for hundreds of years $[8,46,47]$. This increased susceptibility is thought to be due to a genetic "bottleneck" that reduced T-cell receptor diversity and leukocyte antigens associated with the MHC complex [6]. The limited genetic diversity in the Tasmanian tiger is thought to underlie its extinction, and this genetic convergence has contributed to the rapid spread of highly contagious and deadly facial tumors in the Tasmanian devil that is under threat of extinction $[8,47]$. For the new dinosaur population, a lack of genetic diversity may result in a hyper-susceptibility to pathogens $[6,48]$.

With the exception of an unknown virus encoded in the dinosaur genome, most of the health threats to dinosaurs will be from current pathogens. Morbidities and mortalities associated with these pathogens will be augmented by the lack of genetic diversity in the dinosaurs; thus, proactively addressing these problems is critical.

\section{Conclusions}

Investigations into many potential pharmacological agents will be necessary to care for dinosaurs if they are ever resurrected, and the same should be considered for current populations that are seriously endangered and species that have more recently become extinct (e.g., the dodo bird). Alpha-2-adrenergic receptor agonists, opioids, and benzodiazepines are potential dinosaur tranquilizers, but further comparative research needs to be performed to establish safety and efficacy in the new species. The risk of reviving an occult retrovirus or potentiating the spread of an avian, reptilian, or zoonotic disease demands that the new species should be strictly quarantined to establish disease risk. This quarantine would also serve to protect the new species from endemic diseases to which they may be susceptible, especially given the low genetic variability of the resurrected population. Comparative pharmacology, uncovering critical subcomponents of diseases and molecular analyses of prehistoric genomic data will all be needed to safely revive these creatures.

\section{Acknowledgements}

The junior authors would like to thank their mentors for allowing their participation in this review.

\section{Authors' contributions}

The first 11 authors and the corresponding author all contributed equally to the writing of this review. The other 10 authors had smaller contributions to the writing or editing of this review.

\section{References}

1. Piña-Aguilar RE, Lopez-Saucedo J, Sheffield R, Ruiz-Galaz LI, Barroso-Padilla Jde J, et al. (2009) Revival of extinct species using nuclear transfer: hope for the mammoth, true for the Pyrenean Ibex, but is it time for "conservation cloning"? Cloning Stem Cells 11: 341-6.

2. Romano M, Maganuco S, Nosotti S, Manucci F (2015) Taking up the legacy of Waterhouse Hawkins and Owen: art and science for a new Italian project to bring back dinosaurs to life. Hist Biol 28: 1014-25.

3. Riviere JE, Martin-Jimenez T, Sundlof SF, Craigmill AL (1997) Interspecies allometric analysis of the comparative pharmacokinetics of 44 drugs across veterinary and laboratory animal species. J Vet Pharmacol Ther 20: 453-63.

4. Klenk K, Snow J, Morgan K, Bowen RA, Stephens M, et al. (2004) Alligators as West Nile Virus amplifiers. Emerg Infect Dis 10: $2150-6$.

5. Ebani W, Fratini F (2005) Bacterial Zoonoses Among Domestic Reptiles. Annali Fac Med Vet LVII: 85-91.

6. Radwan J, Biedrzycka A, Babik W (2010) Does reduced MHC diversity decrease viability of vertebrate populations? Biological Conservation 143 : 537-44.

7. Grueber CE, Wallis GP, Jamieson IG (2013) Genetic drift outweighs natural selection at toll-like receptor (TLR) immunity loci in a re-introduced population of a threatened species. Mol Ecol 22: 4470-82. 
8. Kreiss A, Cheng Y, Kimble F, Wells B, Donovan S, et al. (2011) Allorecognition in the Tasmanian devil (Sarcophilus harrisii), an endangered marsupial species with limited genetic diversity. PLoS One 6: 1-8.

9. Wang, SC, Dodson P (2006) Estimating the diversity of dinosaurs. Proc Natl Acad Sci U S A 103: 13601-5.

10. Riviere JE (2009) Veterinary Pharmacology and Therapeutics. Wiley, Ames, Iowa.

11. Alföldi J, Di Palma F, Grabherr M, Williams C, Kong L, et al. (2011) The genome of the green anole lizard and a comparative analysis with birds and mammals. Nature 477: 587-91.

13. Hudson BD, Murdoch H, Milligan G (2013) Minireview: The effects of species ortholog and SNP variation on receptors for free fatty acids. Mol Endocrinol 27: 1177-87.

12. Schwinn DA, Johnston GI, Page SO, Mosley MJ, Wilson KH, et al. (1995) Cloning and pharmacological charcterization of human alpha-1 adrenergic receptors: sequence corrections and direct comparisons with other species homologues. J Pharmacol Exp Ther 272: 134-42.

14. Pryce CR (2008) Postnatal ontogeny of expression of the corticosteroid receptor genes in mammalian brains: inter-species and intra-species differences. Brain Res Rev 57: 596-605.

15. Sandmeier P (2000) Evaluation of Metetomidine for short-term immobilization of domestic pigeons (Columbia livia) and amazon parrots (Amazona species). J Avian Med Surg 14: 8-14.

16. Read MR (2004) Evaluation of the use of anesthesia and analgesia in reptiles. J Am Vet Med Assoc 224: 547-52.

17. Mosley CAE (2005) Anesthesia and analgesia in reptiles. J Exot Pet Med 14: 243-62.

18. Goldstein DB, Tate SK, Sisodiya SM (2003) Pharmacogenetics goes genomic. Nat Rev Genet 4: 937-47.

19. Haigh JC, Gates CC (1995) Capture of wood bison (Bison bison athabascae) using carfentanil-based mixtures. J Wildl Dis 31: 37-42.

20. Galloway DS, Coke RL, Rochat MC, Radinsky MA, Hoover JP, et al. (2002) Spinal compression due to atlantal vertebral malformation in two African lions (Panthera leo). J Zoo Wildl Med 33: 249-55.

21. Ulmanen MS, Pekkarinen T, Hietala OA, Birr EA, Jalovaara P (2005) Osteoinductivity of partially purified native ostrich (Struthio camelus) bone morphogenetic protein: comparison with mammalian species. Life Sci 77: 2425-37.

22. Hughes RA, Baker MR (1995) Baseline performance as determinant of morphine hypo- and hyperalgesia in domestic fowl. Exp Clin Psychopharm 3: 3-8.

23. Snyder SH, Pasternak GW (2003) Historical review: Opioid receptors. Trends Pharmacol Sci 24: 198-205.

24. Stevens CW, Brasel CM, Mohan S (2007) Cloning and bioinformatics of amphibian mu, delta, kappa, and nociceptin opioid receptors expressed in brain tissue: evidence for opioid receptor divergence in mammals. Neurosci Lett 419: 189-94.

25. Zamanian M, Kimber M, McVeigh P, Maule A, Carlson S, Day T (2011) The repertoire of G protein-coupled receptors in the human parasite Schistosoma mansoni and the model organism, Schmidtea mediterranea. BMC Genomics 12: 596.

26. Guerrieri D, Rapp E, Roman M, Thelander G, Kronstrand R (2017) Acrylfentanyl: Another new psychoactive drug with fatal consequences. Forensic Sci Int 277: e21-9.

27. Benyhe S, Hoffmann G, Varga E, Hosztafi S, Toth G, et al. (1989) Effects of oxymorphazone in frogs: long lasting antinociception in vivo, and apparently irreversible binding in vitro. Life Sci. 44: 1847-57.

28. Griffin CE 3rd, Kaye AM, Bueno FR, Kaye AD (2013) Benzodiazepine pharmacology and central nervous system mediated effects. Ochner J 13: 214-23.

29. Mans C, Guzman DS, Lahner LL, Paul-Murphy J, Sladky KK (2012) Sedation and physiologic response to manual restraint after intranasal administration of midazolam in Hispaniolan Amazon parrots (Amazona ventralis). J Avian Med Surg 26: 130-9.

30. Arnett-Chinn ER, Hadfield CA, Clayton LA (2016) Review of intramuscular midazolam for sedation in reptiles at the national aquarium, Baltimore. J Herpetol Med Surg 26: 59-63.

31. Rubin GM, Yandell MD, Wortman JR, Gabor Miklos GL, Nelson CR, et al. (2000) Comparative Genomics of Eukaryotes. Science 287: 2204-16.

32. Webster RG, Peiris M, Chen H, Guan Y (2006) H5N1 outbreaks and enzootic influenza. Emerg Infect Dis 12: 3-8.

33. Besser JM (2017) Salmonella epidemiology: A whirlwind of change. Food Microbiol 30: 1-5.

34. Finstad S, O'Bryan CA, Marcy JA, Crandall PG, Ricke SC (2012) Salmonella and broiler processing in the United States: relationship to foodborne salmonellosis. Food Res Int 45: 789-94.

35. Friedman CR, Torigian C, Shillam PJ, Hoffman RE, Heltzel D, et al. (1998) An outbreak of salmonellosis among children attending a reptile exhibit at a zoo. J Pediatr 132: 802-7.

36. Uren AG, Kool J, Berns A, van Lohuizen M (2005) Retroviral insertional mutagenesis: past, present and future. Oncogene 24: 7656-72.

37. Dunlap KA (2006) The role of ovine betaretroviruses in uteroplacental function. [College Station, Texas]: Texas A\&M University.

38. Godfrey SS1, Nelson NJ, Bull CM (2011) Ecology and dynamics of the blood parasite Hepatazoon tuatarae (Apicomplexa), in tuatara (Sphenodon punctatus) on Stephen's Island, New Zealand. J Wildl Dis 47: 126-39.

39. Peñalver E, Arillo A, Delclos X, Peris D, Grimaldi DA, et al. (2017) Ticks parasitised feathered dinosaurs as revealed by Cretaceous amber assemblages. Nat Commun. 8: 1-13.

40. McConnell CS, Zavada MS (2013) The occurrence of an abdominal fauna in an articulated tapir (Tapirus polkensis) from the Late Miocene Gray Fossil Site, Northeastern Tennessee. Integr Zool 8: 74-83.

41. Poinar G Jr, Boucot AJ (2006) Evidence of intestinal parasites of dinosaurs. Parasitology. 133: 245-9.

42. Dentzien-Dias PC, Poinar Jr G, de Figueiredo AE, Pacheco AC, Horn BLD, et al. (2013) Tapeworm eggs in a 270 million-year-old shark coprolite. PLoS One 8: 1-4.

43. Sorci G (2013) Immunity, resistance and tolerance in bird-parasite interactions. Parasite Immunol 35: 350-61.

44. Fitzgerald KT, Newquist KL (2008) Poisonings in reptiles. Vet Clin North Am. Exot Anim. Pract 11: 327-57.

45. Casadevall A (2005) Fungal virulence, vertebrate endothermy, and dinosaur extinction: is there a connection? Fungal Genet Biol 42: 98-106.

46. Menzies BR, Renfree MB, Heider T, Mayer F, Hildebrandt TB, et al. (2012) Limited genetic diversity preceded extinction of the Tasmanian tiger. PLoS One 7: $1-7$. 
47. Morris K, Austin JJ, Belov K (2013) Low major histocompatibility complex diversity in the Tasmanian devil predates European settlement and may explain susceptibility to disease epidemics. Biol Lett 9: 20120900.

48. Blum JS, Wearsch PA, Cresswell P (2013) Pathways of antigen processing. Annu Rev Immunol 31: 443-73.

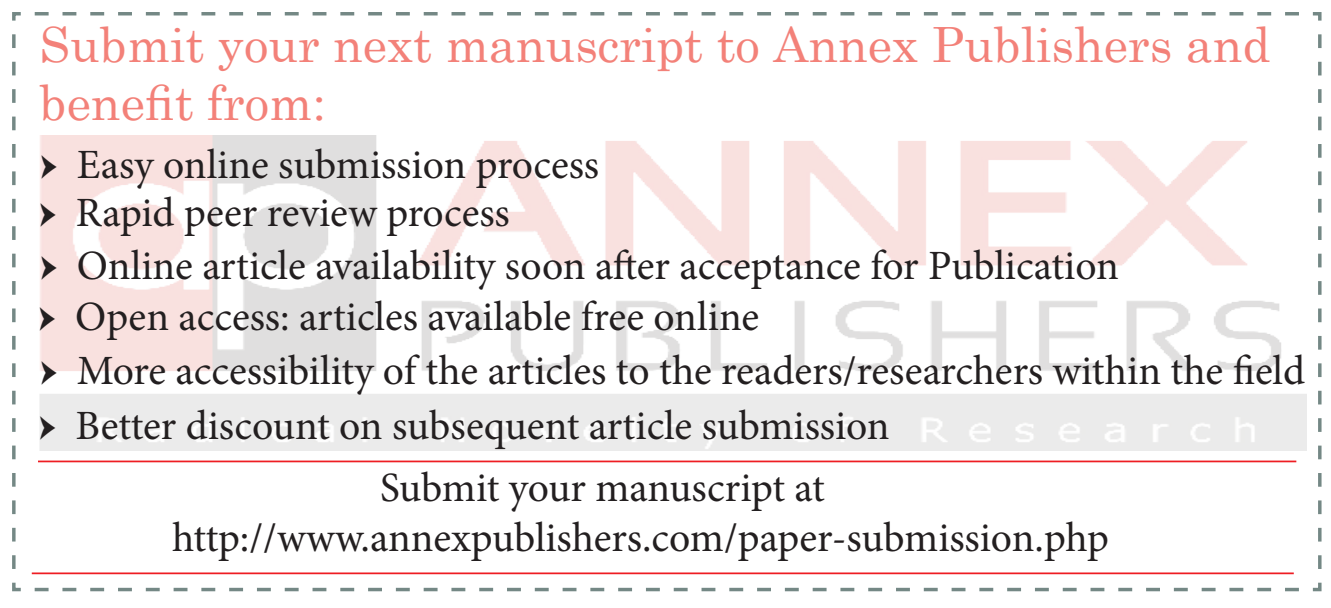

